\title{
Simultaneous nested modeling from the synoptic scale to the LES scale for wind energy applications
}

Liu, Yubao; Warner, Tom; Liu, Yuewei; Vincent, Claire Louise; Wu, Wanli; Mahoney, Bill; Swerdlin, Scott; Parks, Keith; Boehnert, Jennifer

Published in:

Journal of Wind Engineering \& Industrial Aerodynamics

Link to article, DOI:

10.1016/j.jweia.2011.01.013

Publication date:

2011

Link back to DTU Orbit

Citation (APA):

Liu, Y., Warner, T., Liu, Y., Vincent, C. L., Wu, W., Mahoney, B., Swerdlin, S., Parks, K., \& Boehnert, J. (2011). Simultaneous nested modeling from the synoptic scale to the LES scale for wind energy applications. Journal of Wind Engineering \& Industrial Aerodynamics, 99(4), 308-319. https://doi.org/10.1016/j.jweia.2011.01.013

\section{General rights}

Copyright and moral rights for the publications made accessible in the public portal are retained by the authors and/or other copyright owners and it is a condition of accessing publications that users recognise and abide by the legal requirements associated with these rights.

- Users may download and print one copy of any publication from the public portal for the purpose of private study or research.

- You may not further distribute the material or use it for any profit-making activity or commercial gain

- You may freely distribute the URL identifying the publication in the public portal 


\title{
Simultaneous nested modeling from the synoptic scale to the LES scale for wind energy applications
}

\author{
Yubao Liu ${ }^{\mathrm{a}, *}$, Tom Warner ${ }^{\mathrm{a}}$, Yuewei Liu ${ }^{\mathrm{a}}$, Claire Vincent ${ }^{\mathrm{b}}$, Wanli Wu ${ }^{\mathrm{a}}$, Bill Mahoney ${ }^{\mathrm{a}}$, Scott Swerdlin ${ }^{\mathrm{a}}$, \\ Keith Parks ${ }^{c}$, Jennifer Boehnert ${ }^{\mathrm{a}}$ \\ a National Center for Atmospheric Research, Boulder, CO, USA \\ ${ }^{\mathrm{b}}$ Wind Energy Division, Risø National Laboratory for Sustainable Energy, Danish Technical University, Roskilde, Denmark \\ ${ }^{\mathrm{c}}$ Xcel Energy, Boulder, CO, USA
}

\section{A R T I C L E I N F O}

Available online 24 February 2011

Keywords:

LES

Multiscale modeling

Wind energy

WRF

$4 \mathrm{D}$ data assimilation

NWP

\begin{abstract}
A B S T R A C T
This paper describes an advanced multi-scale weather modeling system, WRF-RTFDDA-LES, designed to simulate synoptic scale ( $\sim 2000 \mathrm{~km})$ to small- and micro-scale $(\sim 100 \mathrm{~m})$ circulations of real weather in wind farms on simultaneous nested grids. This modeling system is built upon the National Center for Atmospheric Research (NCAR) community Weather Research and Forecasting (WRF) model. WRF has been enhanced with the NCAR Real-Time Four-Dimensional Data Assimilation (RTFDDA) capability. FDDA is an effective data assimilation algorithm, which is capable of assimilating diverse weather measurements on model grids and seamlessly providing realistic mesoscale weather forcing to drive a large eddy simulation (LES) model within the WRF framework. The WRF based RTFDDA LES modeling capability is referred to as WRF-RTFDDA-LES. In this study, WRF-RTFDDA-LES is employed to simulate real weather in a major wind farm located in northern Colorado with six nested domains. The grid sizes of the nested domains are 30,10,3.3, 1.1, 0.370 and $0.123 \mathrm{~km}$, respectively. The model results are compared with wind-farm anemometer measurements and are found to capture many intra-farm wind features and microscale flows. Additional experiments are conducted to investigate the impacts of subgrid scale (SGS) mixing parameters and nesting approaches. This study demonstrates that the WRF-RTFDDA-LES system is a valuable tool for simulating real world microscale weather flows and for development of future real-time forecasting system, although further LES modeling refinements, such as adaptive SGS mixing parameterization and wall-effect modeling, are highly desired.
\end{abstract}

(c) 2011 Elsevier Ltd. All rights reserved.

\section{Introduction}

Wind energy prediction requires regional short-term (0-24 h) weather forecasts to support intra-hour, multi-hour and day lead-time decision-making. Knowledge of small and microscale (100-10 km) flows and dynamics, as well as the model capabilities for realistic simulation of these flows at or around wind farms is highly desired for wind power prediction. Microscale weather modeling is also an effective way to support wind turbine siting and turbine operations. Although encouraging advances in microscale flow modeling, including the evolution of different technologies and flavors of LES and CFD (Computational Fluid Dynamics) models, have been made in the last decade, the modeling ability for microscale flows associated with real weather at typical wind farm scales is still very limited. In fact, microscale weather flow

\footnotetext{
* Correspondence to: National Center for Atmospheric Research, 3450 Mitchell Lane, Boulder, CO 80301, USA. Tel.: +1(303)4972811; fax: +1(303)4978401.

E-mail addresses: yliu@ucar.edu (Y. Liu), clav@risoe.dtu.dk (C. Vincent), keith.parks@xcelenergy.com (K. Parks).
}

models encounter many challenges. One is the difficulty to seamlessly drive CFD/LES models with realistic weather forcing. Another challenge is regarding to taking account of the atmospheric physics processes, including long wave and solar radiation and realistic land surface forcing in fine scales. Therefore existing microscale models have mostly focused on idealized case study, with idealized initial conditions and/or boundary conditions and/or highly simplified atmospheric physics.

In the last ten years, NCAR has developed a Real-Time FourDimensional Data Assimilation (RTFDDA) weather forecasting system (Liu et al., 2006, 2008a,b) to support regional and local applications such as wind energy forecasting. RTFDDA, built upon WRF, is a rapidly cycling weather forecasting system with the capability of effectively combining all available weather observations with the full-physics WRF model to produce accurate multiscale four dimensional (4D) weather information from synoptic scale to microscale $(<2 \mathrm{~km})$. Recently, RTFDDA has been downscaled to LES scale modeling grids, which allows successive downscaling from synoptic-scale numerical weather predictions (based on global models) to regional weather predictions 
(mesoscale weather processes), and further to small- and microscale weather modeling with LES, hereafter, WRF-RTFDDA-LES. Through the nested-down grid refinements, this modeling system provides a unique ability for simulating real microscale weather processes by incorporating realistic mesoscale weather forcing (through the lateral boundaries), high-resolution terrain and land use, and physical processes of solar and long wave radiation and cloud microphysics.

In this paper, we first describe the WRF-RTFDDA-LES modeling system in Section 2. The model configuration and parameter settings for simulating a two-day microscale weather process on a moderate-size wind farm are introduced in Section 3, followed by the model output analysis and verification using dense wind farm observation data in Section 4. Sensitivity studies on subgrid scale (SGS) mixing and 1-way versus 2-way nested-grid algorithms are presented in Sections 5 and 6 . The summary and conclusions are given in Section 7.

\section{NCAR WRF-RTFDDA-LES model}

WRF is an advanced mesoscale weather model that incorporates the state-of-the-art scientific and engineering achievements in research and operational weather model developments (Skamarock et al., 2008). WRF is used and continuously improved by a broad network of academic, private and public operational weather institutions and users. The model contains advanced physics schemes and multi-physics parameterizations for modeling all major atmospheric processes, thus it allows the modeling of a full spectrum of real and idealized weather processes from global to mesoscale with grid spacing down to $500 \mathrm{~m}$. Recently, 3D Turbulence closure (Smagorinsky, 1993) and prognostic turbulent kinetic energy (TKE) closure schemes for subgrid scale (SGS) were added into WRF. These schemes are particularly useful in facilitating the simulation of microscale weather at LES scales (Moeng et al., 2007).

WRF-RTFDDA is an enhanced WRF modeling system, which is capable of assimilating diverse weather observations (Liu et al., 2008a). The FDDA system employs a Newtonian relaxation approach to continuously nudge the model states toward all available observations with weights specified as functions of space and time according to observation location and time. The main objective is to obtain a dynamical balance and physical consistency between measured data and numerical solution of the model. For multi-scale modeling, FDDA parameters can be adjusted for each nested grid to ensure the consistency with the spatial and temporal scale of the circulations that are resolved on the grid. In the last few years, WRF-RTFDDA has been applied to support more than 30 national and international weather-critical applications running with a fine-mesh domain at grid spacing of $0.5-45 \mathrm{~km}$ in both real-time operations and retrospective modeling studies.

Recently, WRF-RTFDDA has been further developed to simulate small- and micro-scale circulations on LES scale grid and the new system is referred to as WRF-RTFDDA-LES. It is designed for multi-scale modeling down to microscale weather processes for focused geographical areas. WRF-RTFDDA-LES makes use of simultaneous nest-down approach with fine-mesh domains running at LES scale. The model simulates mesoscale weather on the coarser grids (DX $>500 \mathrm{~m}$ ) with a planetary boundary layer (PBL) parameterization along with other model physics parameterizations and FDDA. In contrast, for the fine-mesh LES modeling, we substitute the PBL scheme with 3D prognostic TKE diffusion scheme (Skamarock et al., 2008), while all the other atmospheric physics processes (i.e. radiation, cloud microphysics, etc.) are parameterized in the same way as in the coarse meshes. On fine mesh model domains, boundary layer turbulence is explicitly simulated by the 3D TKE scheme. The simultaneous nested-down approach allows continuous forcing of mesoscale weather at lateral boundaries of the LES model domains to ensure realistic environmental weather forcing for the LES simulation.

\section{Simulation of intra-farm wind variation}

Local wind flows are complex products of multi-scale weather interactions, and they can be influenced by many factors, such as local and regional scale topography, land-surface and soil heterogeneity, and nonlinear scale interactions. All these factors can result in large variations of sustained winds (e.g. 1-min average wind) over a distance of $\sim 100 \mathrm{~m}$ in a few minutes, which are often observed by wind turbine (hub-height) anemometers in inland wind farms, such as a wind farm located at the northeastern Colorado boundary line in the Rocky Mountain Front Range region. The local weather in the wind farm is significantly influenced by the mountain ranges. This wind farm, hereafter referred to as COfarm, covers an area of about $10 \times 15 \mathrm{~km}^{2}$ (Fig. 1), and consists of 274 wind turbines sitting $400-700 \mathrm{~m}$ apart and two meteorological towers.

From November 14 to 16,2008 , wind speeds measured by the wind turbine nacelle anemometers at the wind farm vary from 2 to $15 \mathrm{~m} / \mathrm{s}$. Fig. 1 is a snapshot of spatial wind speed variation across the wind turbines during this study period. The wind power generated by each wind turbine is proportional to the cube of wind speed at turbine hub height for wind speeds between 5 and $15 \mathrm{~m} / \mathrm{s}$, thus fluctuations in wind speed are amplified by the power curve of the turbines, and modeling intra-farm wind variations in such real weather conditions is of great interest. On the other hand, the dense wind measurements in wind farm are very important in facilitating WRF-RTFDDA-LES model verification capability and understanding the model limitations in order to enhance our knowledge of real world microscale weather phenomena.

The WRF-RTFDDA-LES model is configured to simulate the weather conditions at the COfarm in northeastern Colorado during the period of 14-16 November 2008, with six simultaneous nested-grid domains (Fig. 2). The grid sizes of the six domains are $30,10,3.3,1.1,0.370$ and $0.123 \mathrm{~km}$, respectively. Domain 1 is large enough to cover the synoptic scale weather of several thousand kilometers, while Domain 7 encloses the small region of the COfarm. Domains 2-5 simulate the weather processes ranging from synoptic scales to microscales. Domains 3 and 4 cover major Rocky Mountain ranges that have significant impact on the Front Range weather. Domain 5 cuts through the Front Range slope of the mountains. The WRF model employs etatype terrain following vertical coordinate (Skamarock et al., 2008), which is defined with surface and upper-air pressures. The coordinates are stretched with heights and allow relatively dense levels in the lower levels. In this study, 37 vertical levels were set for all domains. There are about 12 model levels positioned in the lowest $1 \mathrm{~km}$ layer. The WRF vertical levels change slightly with terrain height and vertical pressures. The heights of the lowest 12 model levels are, approximately, 15, 53, $105,163,228,300,381,471,572,685,811$, and $952 \mathrm{~km}$ above ground level.

Atmospheric radiation, clouds and land surface forcing are simulated in this modeling study. Planetary Boundary Layer parameterizations and FDDA are applied for the four coarse-mesh domains, whereas the two finest meshes are run with the LES settings. The FDDA continuously assimilates diverse synoptic and asynoptic weather observations and provides continuous boundary forcing to those two fine-mesh domains for LES modeling. 


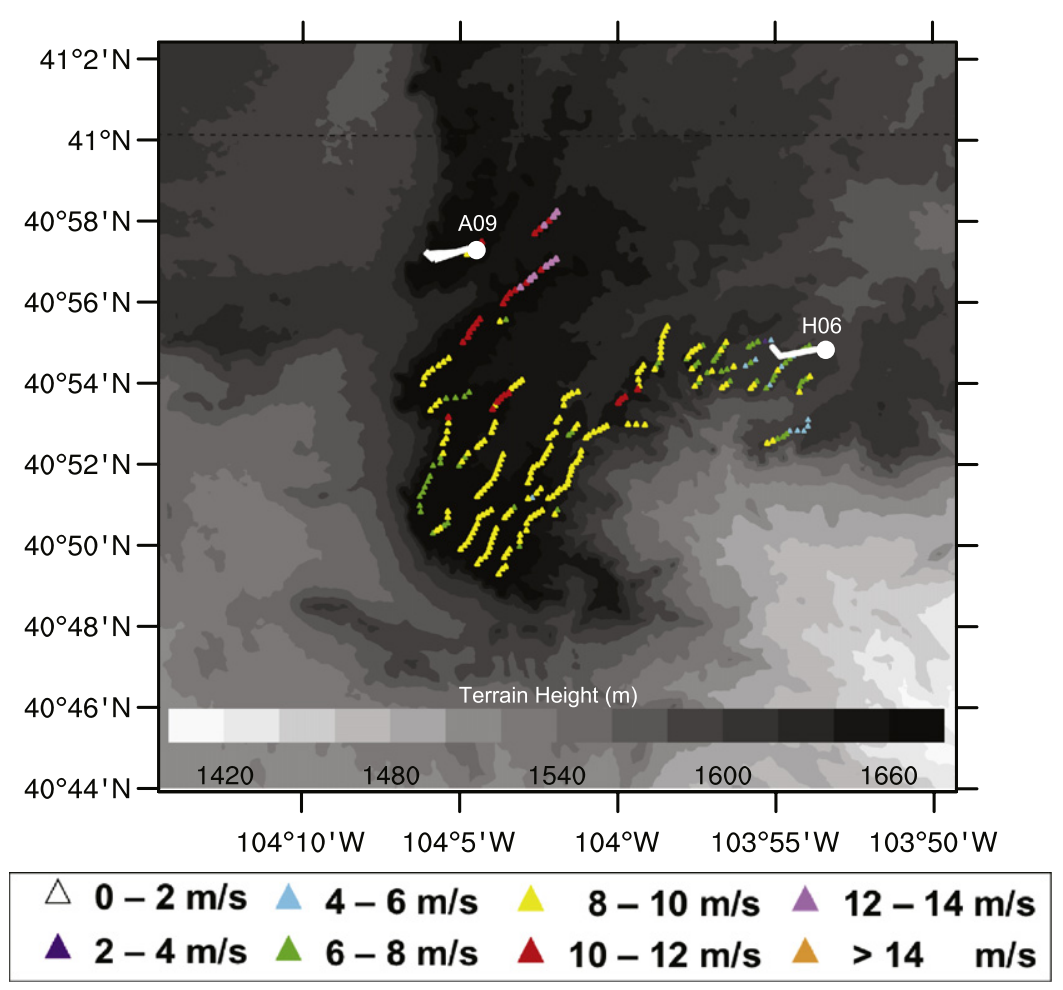

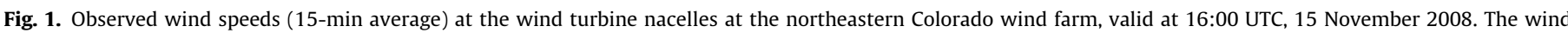

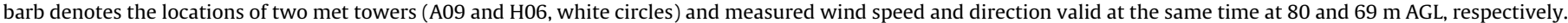
The background shade represents terrain height in meters.

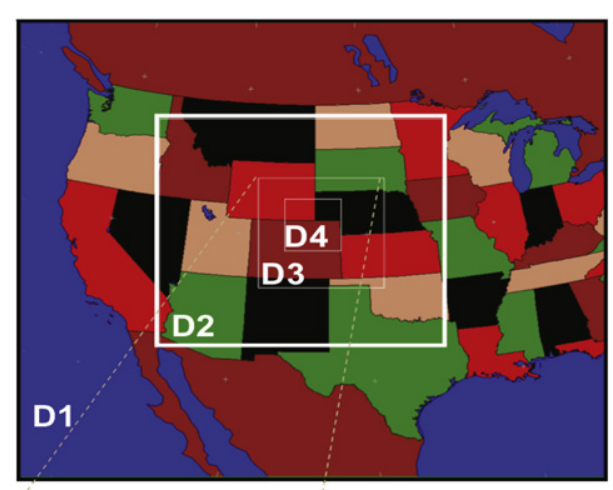

$\begin{array}{lcc}\text { DOM: } & \Delta \mathrm{x} & \text { Grid } \\ \text { D1: } & 30 \mathrm{~km} & 128 \times 114 \\ \text { D2: } & 10 \mathrm{~km} & 184 \times 169 \\ \text { D3: } & 3.3 \mathrm{~km} & 244 \times 247 \\ \text { D4: } & 1.1 \mathrm{~km} & 331 \times 346 \\ \text { D5: } & 370 \mathrm{~m} & 505 \times 490 \\ \text { D7: } & 123 \mathrm{~m} & 280 \times 271\end{array}$
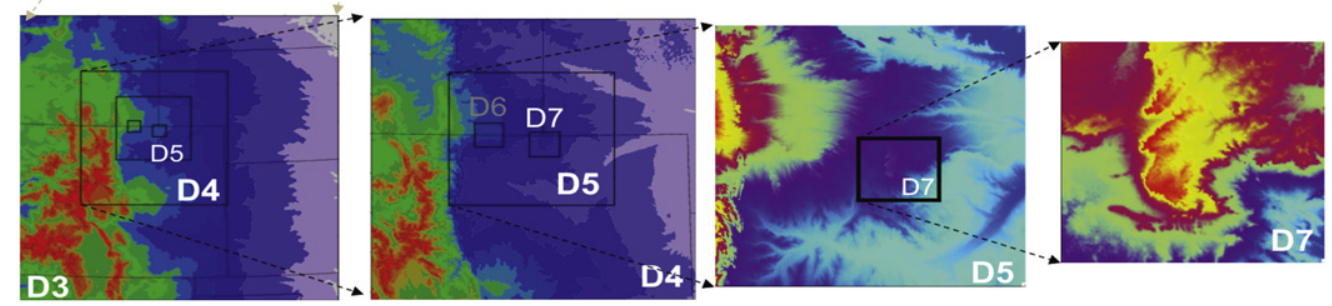

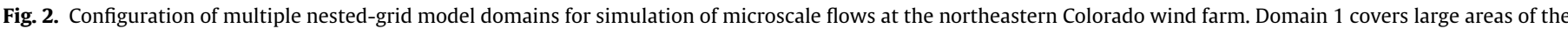

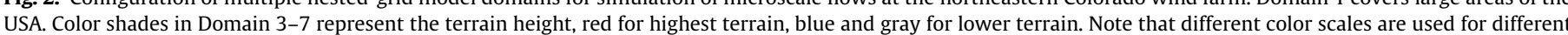

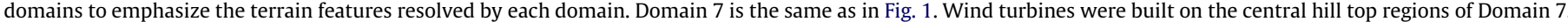

\section{Analysis and verification of model results}

The main research interests include: (1) evaluating model capability in simulating rich intra-farm wind features and their evolutions, as seen from the high spatial and temporal turbine hub-height wind speed observations; (2) assessing the potential uses of the model as the computing power grows for real-time forecasting; (3) investigating the importance of two-way/one- way nesting approach between mesoscale and LES modeling grids; (4) studying of the limitations of mesoscale weather models that make use of parameterized boundary layer mixing schemes; and (5) studying of the needs for the further understanding of the transition from full parameterization of large eddies in $\sim 1 \mathrm{~km}$ grid model to explicit modeling of the large eddies in domains with $\sim 10 \mathrm{~m}$ grids, and parameter adjustment for corresponding SGS parameterization. 
The simulation was cold-started from NOAA National Center of Environment Prediction (NCEP) GFS (Global Forecasting System) model analysis at 00 UTC, November 14, 2008 and then continuously run for $54 \mathrm{~h}$, when a large scale circulation ramp followed by a ramp down event occurred from around 00:00 UTC, November 15 , and a moderate wind surge (wind/power ramp up) at the wind farm occurred at about 17:00 UTC, November 15 (shown in the top panel of Fig. 3). The model outputs were written out every 10 min. The coarse-resolution imperfect initial conditions cause known "spin-up" processes for the first 6-12 h model simulation that can adversely affect the modeling result and thus one needs to analyze the first $0-12 \mathrm{~h}$ model outputs with great caution. Diurnal forcing of the solar and long-wave radiation is simulated, which leads to a dramatically evolution of the PBL depth and mixing during the two-day modeling period (not shown).

The model reasonably captures the overall features of both large- and small-scales circulations for the two-day period in different domains. It should be noted that FDDA, which assimilates standard radiosonde observations, surface observations, and a large amount of non-conventional data, including commercial airline report, wind profilers, satellite data, was only activated on the mesoscale modeling domains (Domains 1-4). The wind farm observations themselves, which are used for verification purposes, are not assimilated. This makes the direct comparison between the LES simulations on the fine grids and the observations more meaningful. To verify the model with the wind farm

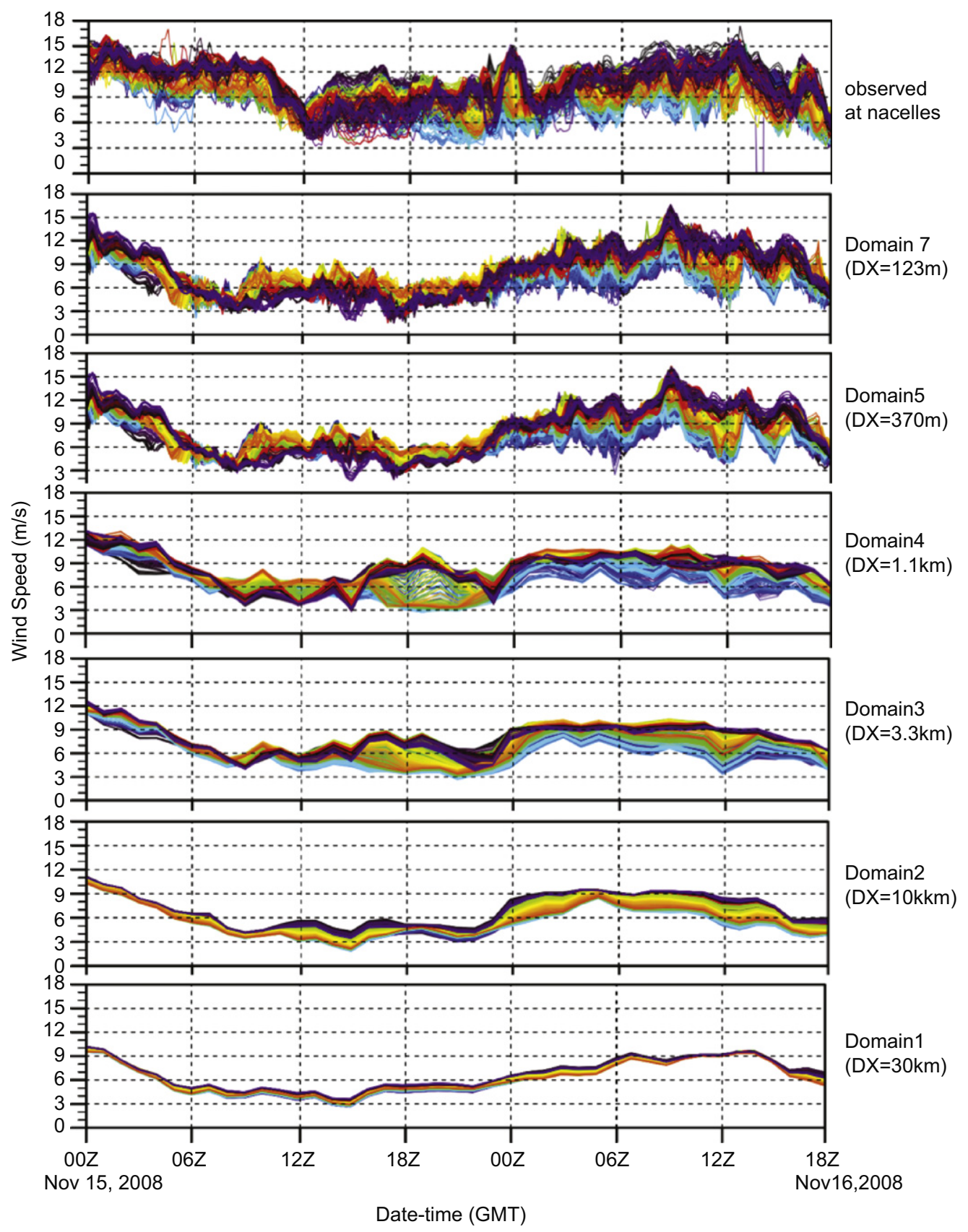

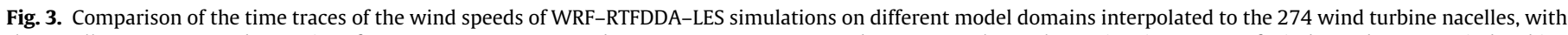

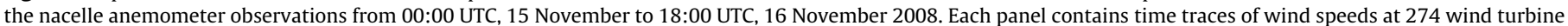
locations and the colors are for different turbines. 


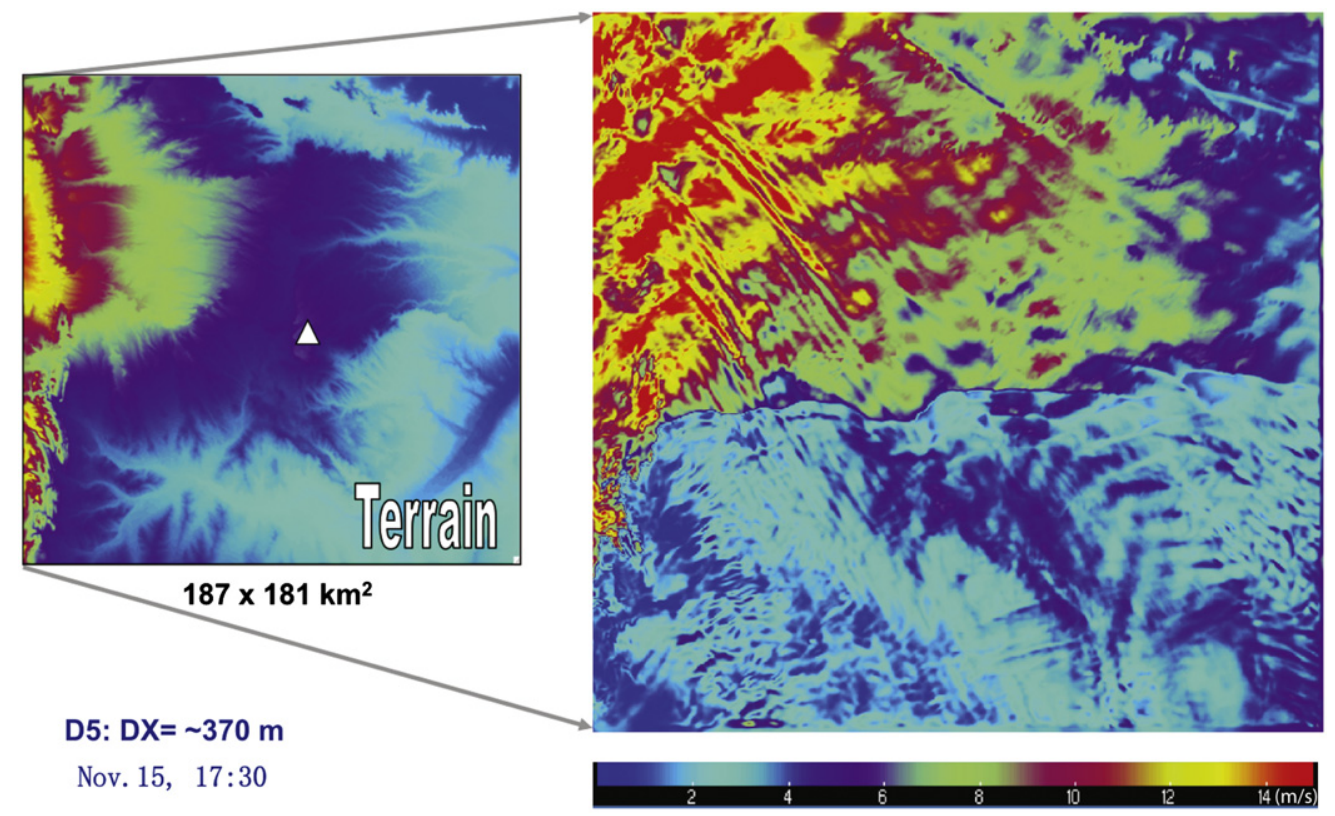

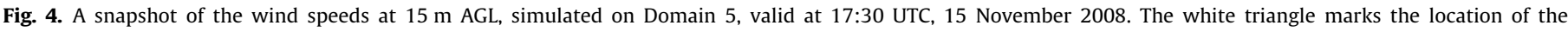
northeastern Colorado wind farm selected for study.

observations, the first step is to interpolate the modeled wind output to the wind turbine locations at the hub height. With these derived data, statistics based on 274 observation-model wind pairs at every 10 min can be computed. A possible shortcoming of the approach is that the observations will be influenced by both the wakes of the neighboring turbines, and flow distortions near the towers and nacelles. Neither of these effects is taken into account here, but is expected that the errors introduced will be relatively small compared to the errors in the model. Correcting for these effects is an interesting and important area for further exploring the usefulness of hub-height wind speed observations.

Wind turbines are typically equipped with an anemometer positioned on the top of the turbine nacelle behind blade disk. Owing to the aerodynamic effect of nacelle geometries and the rotated blades, the wind speed measurements at the nacelle sites can differ from the environmental meteorological winds by 0.5-2 m/s for typical 1.5-2 MW GE (General Electric) turbines. Wind turbines are typically operated to keep the blade disks facing the incoming wind directions. The nacelle wind speed measurements are used to control wind turbine real-time operations, and they are pretty robust for driving the real-time power outputs of the wind turbines. Thus these wind speeds are fairly reliable for modeling research. Deriving the exact meteorological environmental winds from the nacelle wind measurements are very complicated and not included in this paper.

The apparent advantage and necessity of high-resolution grid for modeling the intra-farm microscale wind variations can be seen in Fig. 3. The higher the model resolution, the more capable the model is in simulating the inter-turbine wind variations. Moreover, the model exhibits enhanced capability of capturing the large-scale wind ramp events. The finest mesoscale grid (Domain 4) resolves only a trivial part of the observed variations, while the finest LES domain (Domain 7) can capture more than $60 \%$. Obviously, further refinement of the model grid is needed in order to capture more observed inter-turbine wind variations. It should be pointed out that the wind speeds simulated on Domain 7 were obviously underestimated during most of November 15,2008 . Further study should be taken to understand if this is due to the inaccurate synoptic and mesoscale forcing or the limitated coarse horizontal and vertical resolutions of the LES domain.

To describe the multi-scale flow features simulated by highresolution model, a snapshot of the wind speeds at the lowest model level in Domain 5 is given in Fig. 4. Domain 5 covers an area from the high slope of Front Ranges to the foothills. The wind farm under study is located close to the domain center. It can be seen that at the time shown in Fig. 4, the wind surge resulting from a large area of down-slope flows is progressing toward the wind farm. Rich small- and micro-scale flow structures are presented in both the weak wind regime ahead of the surge and the strong winds in the surge. The wave of different scales and orientations can be readily identified. While these waves closely resemble to the cloud morphologies that are frequently observed in the Front Range regions, current weather observation networks unfortunately are far insufficient to adequately verify these features.

It is of great curiosity and interest to see if the intra-farm wind variations simulated by the high-resolution LES model actually resembles patterns of the wind structures in the farm. The observed and modeled wind speeds in Domain 7 at 274 wind turbines are plotted every $10 \mathrm{~min}$. The results are mixed. In general, the model shows more skills in modeling the spatial patterns of the wind in the farm than the absolute wind speed itself. As can be expected, at many times, the model winds are not satisfactorily agreeable with the observed wind speeds. However, there are many episodes when the model captured the observed wind speeds and patterns well as shown in Fig. 5. Obviously, the model results indicate a great potential for future real-time forecasting. However, understanding the driving forces of the errors and the current model limitation for such microscale flows are both challenging and necessary in order to improve the microscale models for real-time forecasting applications.

To get an overall picture of the capability of the high-resolution model for improving wind simulation in the wind farm, statistical variables of the observed and the modeled wind speeds at 274 wind turbines are computed and compared. Fig. 6 compares the simulated turbine site median wind speeds of different domains with the observations. It is apparent that the fine grid 


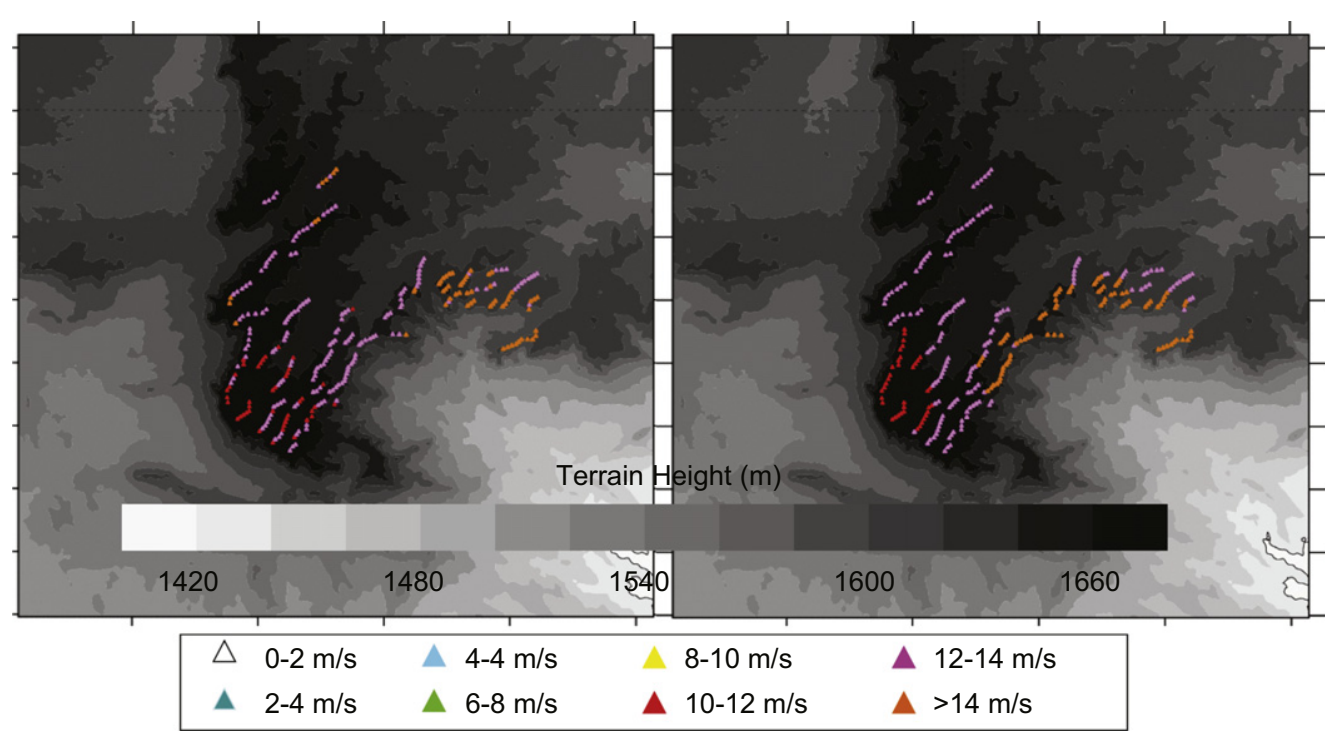

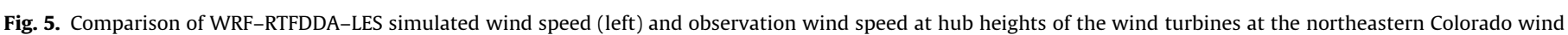
farm. Gray shades show the terrain height same as in Fig. 1.
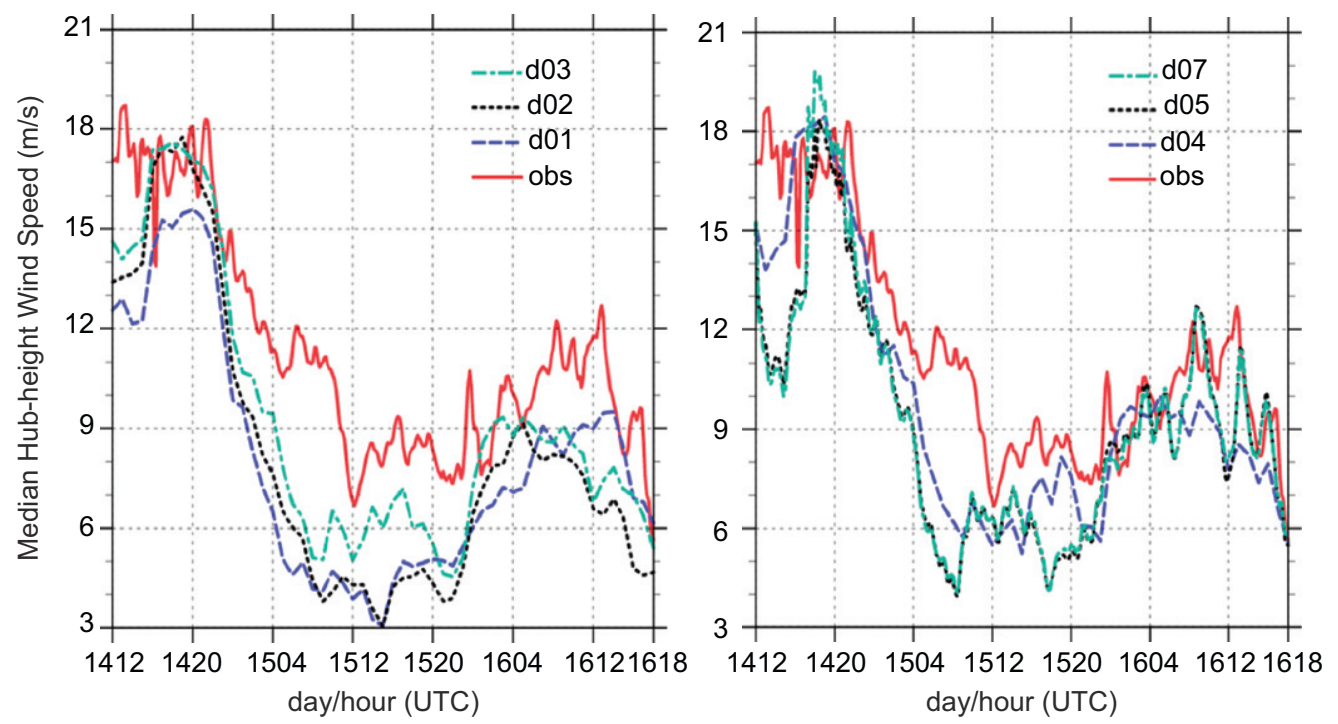

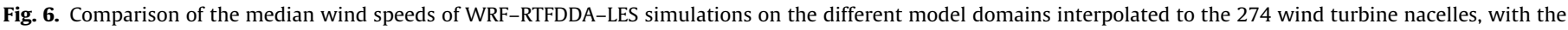
nacelle anemometer observations for the simulation period from 12:00 UTC, 14 November to 18:00 UTC, 16 November 2008.

LES models generally offer improved skills in simulating more accurate winds. The same result is obtained for the 274-turbine mean wind speed. The high-resolution terrain forcing, explicit PBL mixing, and upscaling processes with high-resolution model are among the factors that could be the driving force for the better simulation. Further analysis of model simulations should be undertaken for better understanding of the factors.

Numerical weather prediction models employ column-based PBL schemes to simulate the planetary boundary layer mixing. The WRF model contains both non-local and TKE based PBL schemes (e.g. Hong and Pan, 1996; Janjic, 2002). Although these PBL mixing schemes are able to simulate the basic features of the diurnal evolution of PBL properties, they encounter a great challenge in accurately modeling the momentum/wind profiles in the lowest $300 \mathrm{~m}$ that wind energy forecasting requires. To illustrate this limitation, Fig. 7 shows a snapshot of the vertical wind profiles simulated on the six nested-grid domains. The model winds were interpolated to the Met-tower A09 location.
The wind speed measurements (15 min average) at the two met towers located in the wind farm (Fig. 1) are also included. The mesoscale domains (D01 - D04), which employed the MYJ PBL scheme (Janjic, 2002), yielded similar wind shear structures but with largely different wind speeds. The differences among the simulated winds on the 4 domains are $2-5 \mathrm{~m} / \mathrm{s}$, which is increased with height from the surface to $240 \mathrm{~m}$ above the surface. Furthermore, the model wind speeds seem to respond to grid sizes very irregularly. In Fig. 7, Domain 2 (10 km grid) simulated the weakest winds, Domains 1 (30 km grid) and 3 (3.3 km grid) simulated similar winds, and Domain $4(1.1 \mathrm{~km}$ grid) got the strongest winds.

The two LES domains (Domains 5 and 7) appear to simulate similar wind shear and wind speed, which is mostly true throughout the 54-hour simulation period. The simulated wind shear on the LES domains still differs significantly from the observed winds by the met towers, but they are generally better than the mesoscale model winds. Although idealized modeling studies 


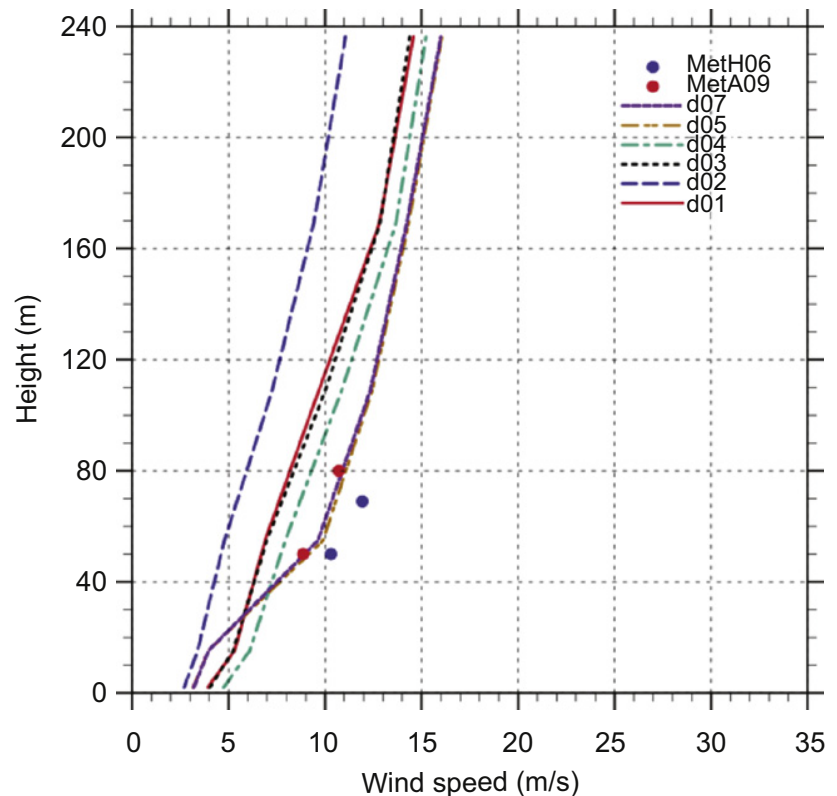

Fig. 7. A snapshot of wind profiles in the lowest $240 \mathrm{~m}$ above ground level extracted from the six nested model domains, at the A09 met-tower location in the northeastern Colorado wind farm, valid at 16 UTC, November 16, 2008. Also plotted are wind observations at two met-towers located in the wind farm.

suggested great capability of the LES models in simulating the boundary layer winds (Kosovic and Curry, 2000; Chow et al., 2005; Sullivan et al., 2003; Mirocha et al., 2010), further study and improved LES model capability in modeling vertical momentum structures for the realistic complex environmental settings, as well as enhanced observation networks are needed. Due to the large computing need, in this study we have not been able to conduct numerical experiments to better understand the factors that affect the PBL wind shears in the mesoscale and LES scale models. We would also like to test the impact of more vertical levels in the lower atmosphere.

\section{Sensitivity to SGS mixing parameters}

For large-eddy scale modeling with grid sizes of tens to hundreds of meters, subgrid-scale (SGS) diffusion parameterization is very important because the models at these scales cannot resolve the small eddies that often play often an important role of mixing. The LES model used in this study was run without a planetary boundary layer scheme, which is built and used for mesoscale weather modeling. Instead, a 3D prognostic Turbulence Kinetic Energy (TKE) based mixing was employed. The TKE closure scheme in WRF is described in Skamarock et al. (2008). In this scheme, the $u$-momentum flux, which appears in the $u$-momentum equation, is related to the vertical gradient of velocity according to:

$\overline{u^{\prime} w^{\prime}}=-K_{m} \frac{\partial u}{\partial z}$,

where the diffusion constant, $K_{m}$, is related to the TKE (e) via a constant, $c_{k}$, and a length scale, $L_{k}$ which relates to the grid spacing of the model.

$K_{m}=C_{k} L_{k} e^{1 / 2}$,

$e$ is calculated prognostically based on contributions from shear production, buoyancy and dissipation. Similar equations are applied to the other two velocity components and the diffusion of heat and moisture. In a study of mesoscale convection on

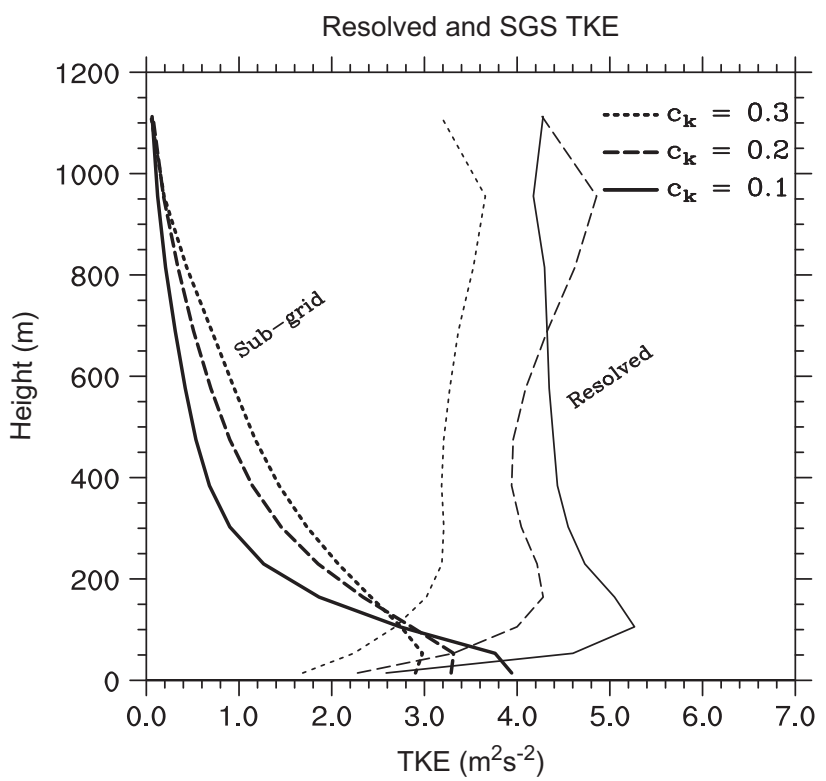

Fig. 8. Subgrid scale and resolved turbulence kinetic energy profiles, averaged over an area of approximately $40 \times 40 \mathrm{~km}^{2}$.

$500 \mathrm{~m}, 2$ and $4 \mathrm{~km}$ grid, Takemi and Rotunno (2003) suggested that a $c_{k}$ value of around 0.125 was sufficiently large to filter grid scale noise from the model, and Moeng et al. (2007) used a $c_{k}$ value of 0.1 in an idealized study of nesting a fine resolution LES domain (of grid spacing $50 \mathrm{~m}$ for a free convective boundary layer, and $20 \mathrm{~m}$ for a shear driven boundary layer) within another, coarser LES domain (of grid spacing $150 \mathrm{~m}$ for the free convective boundary layer and $60 \mathrm{~m}$ for the shear driven boundary layer). However, an optimal value of $c_{k}$ for real weather LES simulations has not been proposed. Basu and Porté-Agel (2006) defined an adaptive methodology for the constant $c_{s}$ in the Smagorinsky turbulence closure scheme, and argued that different values $c_{s}$ were needed for different stability conditions.

In this section, three experiments were run for $6-12 \mathrm{~h}$ of the integration (18UTC, November 14 to 00UTC, November 15, 2008; cf. Fig. 6) of the baseline simulation with $c_{k}$ of $0.1,0.2$ and 0.3 , respectively. The 54-h baseline experiment described in the earlier sections with a default $c_{k}$ of 0.15 and it induces apparent overestimation of wind fluctuations. The 6 -h simulation experiments with different $c_{k}$ were initialized from the baseline experiment which had been run with $c_{k}=0.15$, from the WRF restart files at 18 UTC, November 14, 2008. Therefore, all experiments start from the same initial (restarted) states, and then gradually diverge as their modified $c_{k}$ takes effect. Vertical profiles of subgrid scale and resolved TKE for the three values of $c_{k}$ are given in Fig. 8. The sub-grid scale TKE was calculated prognostically in the model, and was averaged over an area of approximately $40 \times 40 \mathrm{~km}^{2}$. The resolved TKE was calculated over the same area directly from the wind fluctuations about the mean wind within the same area.

$\mathrm{TKE}_{\text {res }}=\frac{(u-\bar{u})^{2}+(v-\bar{v})^{2}+(w-\bar{w})^{2}}{2}$.

Profiles of resolved and subgrid scale TKE are shown in Fig. 8 for three values of $c_{k}$. While comparison of profiles of resolved and subgrid scale TKE is typically done to analyze LES models over flat terrain, it is not an objective measure here because the complex topography contributes to the resolved variance. This means that the profiles in Fig. 8 will not have the same absolute values if calculated over different parts of the domain. Thus only the relative differences between the three experiments will be 

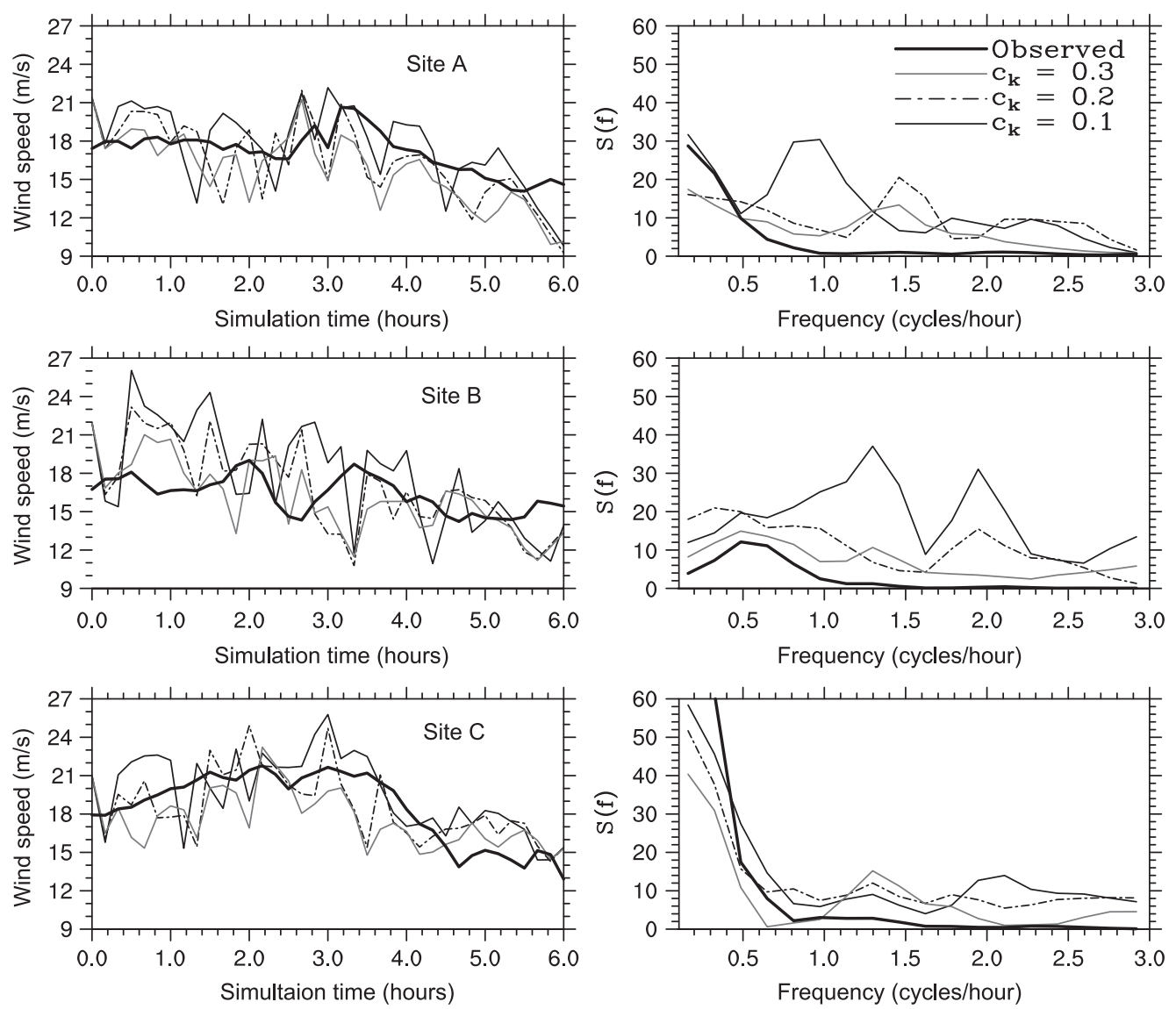

Fig. 9. Forecast and observed time series (left panels) and spectra (right panels) for the three values of $c_{k}$ at three turbine sites.

discussed. The profiles show that as $c_{k}$ increases, the amount of resolved TKE decreases, and the amount of sub-grid-scale TKE increases, apart from in the bottom few model levels. Apparently, increasing $c_{k}$ attenuated the grid-scale fluctuations. In fact, for the study period, the WRF model simulation with a default $c_{k}$ value of 0.15 appears to create too much energy on certain time scales and the simulation with $c_{k}$ value of 0.3 attenuated these overestimations of grid-resolvable energy.

Time series and spectra for the 6 -h experiment at three selected turbine sites (cf. Fig. 12 for the turbine locations) are shown in Fig. 9. It should be pointed out that the $6 \mathrm{~h}$ simulation period may not produce very representative results on the slower time scales ( $>1.5-2 \mathrm{~h}$ ). However, it can be seen from the time series that the amplitude of the fluctuations has been damped on most time scales by increasing $c_{k}$ for all sites, although there is the energy spectra of Site $C$ shows a slight increase in amplitude for 4050 min time scales for $c_{k}=0.3$. Further study is needed to understand if this spectral peak at Site $C$ is associated with the local underlying forcing or other factors. This result again indicates the complexity of the local-scale forcing and scale interaction with real-case modeling. In general, it appears that $c_{k}=0.3$ is preferred with WRF-LES running at $100 \mathrm{~s}$ meters grid spacing. This is just a single $6 \mathrm{~h}$ forecast, thus more simulations and analyses over a variety of weather regimes are required to draw more concrete conclusions on selecting the parameter $c_{k}$.

\section{Comparison of one-way and two-way nesting strategies}

Nested-grid modeling is one of the effective and economical approaches for multiple-scale weather simulation. The other approaches include structural and un-structural adaptive mesh methods built in global weather models (e.g. Côté et al., 1998; Courtier and Geleyn, 1988). Like many other mesoscale weather models, WRF employs the nested-grid approach, where a fixed nested grid ratio of 2-5 can be set to consequently nest the model grids from coarse-mesh grids over large areas down to fine-mesh grids at a small area of focused interest, such as the six-level nested-grid domains configured in this study (Fig. 2). WRF provides two nested-grid strategies: 1-way nesting and 2-way nesting. In 2-way nesting, the coarse-mesh domains provide boundary conditions to their immediate fine-mesh domains at every time step and the fine-mesh domains do not feed back any information to their parent meshes. In contrast, for 2-way nesting, the fine-mesh domains also provide continuous feedback to their parent domains at every time step of the mother domains. In WRF, the fine-mesh feedback is realized by replacing the model fields at the coarse-mesh grids with a smoothed fine-mesh grid values (Smolarkiewicz and Grell, 1990).

There are advantages and disadvantages to the fine-mesh feedback, i.e. running the model with 1-way or 2-way nesting methods. On the one hand, since the fine-mesh grid possesses more accurate solution due to smaller truncation errors and modeling more detailed local forcing, the fine-mesh feedback will provide better solutions to the overlapped coarse-mesh model grids. On the other hand, the inevitable inconsistency between of the model solutions resolved by different grids can sometimes excite noisy adjustments on the coarse-mesh domains, especially in the regions along the internal nested domain boundaries. The baseline simulation discussed in the previous sections were conducted in 1-way nested mode, in which at each time step of the coarse-mesh domains, boundary conditions were derived 

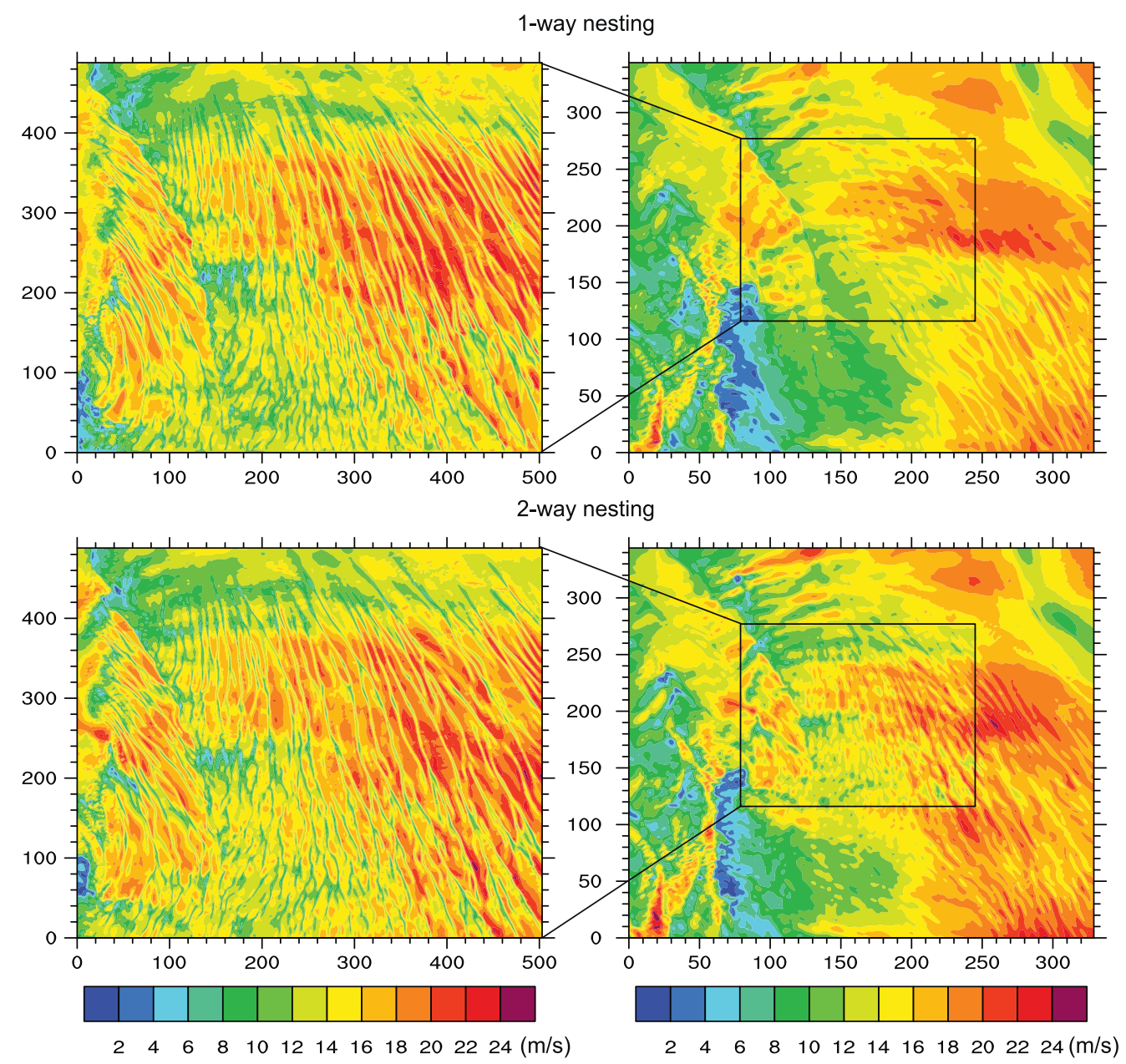

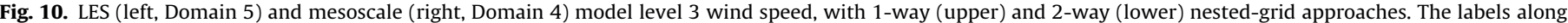
the figure frames are grid numbers of the model domains.

from the coarse mesh and imposed onto the fine-mesh domain boundaries within spatial sponge zone. In this section, we tested the impact of the 2-way nesting approach. Due to the computing limitation, we focused on the same 6 -h period as studied in Section 5 (18 UTC, November 14 to 00 UTC, November 15, 2008) and we only discuss the result for the feedback effect between Domains 4 (mesoscale modeling) and 5 (LES-scale modeling).

The wind speed on the third model level ( $\sim 105 \mathrm{~m}$ above the ground) for the mesoscale (Domain $4, D X=1.1 \mathrm{~km}$ ) and the LES domain (Domain $5, D X=370 \mathrm{~m}$ ) is shown in Fig. 10. The area of the LES domain is framed in the mesoscale domain in each case. Apparently, the 2-way nesting feedback led to enhanced variability from the LES domain to be transferred to the mesoscale domain. This could be regarded as problematic, since this finescale variability can be smaller than those that can be captured explicitly by the mesoscale domain, and could therefore excite computing noises. However, Fig. 10 shows that the higher resolution fluctuations propagate outside the LES domain, on the inflow boundaries as well as the outflow boundaries. This result suggests that the mesoscale model is able to sustain the added detailed structures long enough so that it benefits a greater consistency between the mesoscale domain and the nested LES-scale domain. This result supports the finding by Harris and Durran (2010) that there would be a greater consistency between the parent and child domains with feedback turned on, so that errors arising from reflections off the domain boundary are reduced.

Time series and spectral analysis at the three turbine sites (cf. Fig. 12 for the site locations) for two new experiments with 2-way nesting and $c_{k}$ equal to 0.3 and 0.1 , respectively, are compared with the corresponding 1-way nesting experiments discussed in Section 5 and are shown in Fig. 11. It can be seen that the 2-way nesting significantly damps the overestimation of wind fluctuations at high frequencies for both $c_{k}=0.3$ and 0.1 at Sites A and $\mathrm{B}$, respectively. The experiment with $c_{k}=0.3$ combined with 2-way nesting is most agreeable with the observations. The result at Site $C$ is mixed, but the experiment with $c_{k}=0.3$ and 2-way nesting still outperforms the other experiments in general. As aforementioned in Section 5, the spectra computed here are based on a very short time series, and therefore not very representative. However, it can be seen that they do give a good relative measure of the model wind fluctuations.

The spectral analyses are conducted for all 274 wind turbines at the wind farm. An objective measure was defined as the area under the spectrum between the frequencies of 0.5 and 2.0 cycles/h. This measure represents the kinetic energy contained in the time series on these time scales. The average kinetic energy for each of the four experiments and the observed time series are given in Table 1 . Increasing $c_{k}$ and introducing 2-way nesting feedback both bring about a large decrease in the kinetic energy, there is still significantly too much energy in the model on 

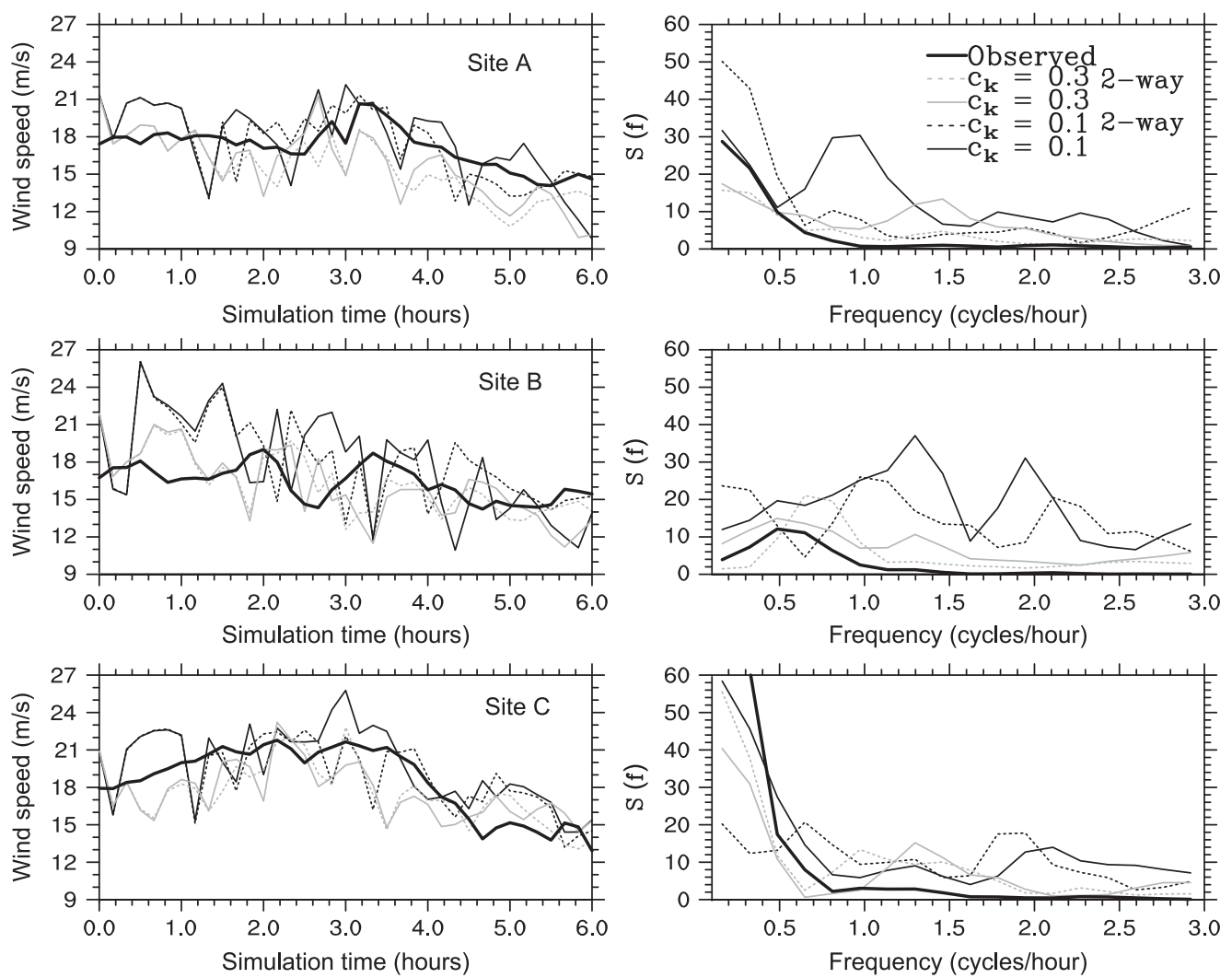

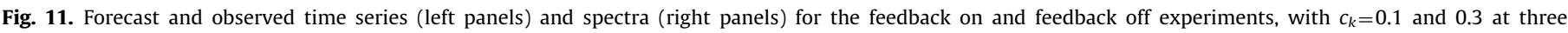
turbine sites.

Table 1

Average kinetic energy $\left(\mathrm{m}^{2} / \mathrm{s}^{2}\right)$ and wind speed RMSE $(\mathrm{m} / \mathrm{s})$ statistics for the four experiments.

\begin{tabular}{llllll}
\hline & $c_{k}=0.1$ & $c_{k}=0.1,2$-way & $c_{k}=0.3$ & $c_{k}=0.3,2$ way & Obs. \\
\hline Average KE & 0.18 & 0.15 & 0.12 & 0.12 & 0.03 \\
SPEED RMSE & 3.57 & 3.44 & 2.83 & 2.86 & \\
\hline
\end{tabular}

these time scales when compared to the observation. Increasing $c_{k}$ decreased the amount of kinetic energy for 228 of the 274 turbines, while turning feedback on (with $c_{k}=0.1$ ) decreased the amount of kinetic energy for 179 of the 274 turbines.

Also shown in Table 1 are the root mean square errors (RMSE) of the wind speeds for the four experiments, averaged over the 274 turbines. The verification computation is for all "modelobservation" wind pairs at each turbine site, every 10 min for the 6 -h experiment periods. The observation values are $10 \mathrm{~min}$ average, centered at $0,10,20,30,40$, and $50 \mathrm{~min}$, while the model values are instantaneous outputs valid at the same times. A total of $\sim 10000$ pairs were used in computing the KE and/or RMSE shown in Table 1. It should be pointed out that the traditional verification scores such as RMSE should be treated with care for high-resolution modeling for time scales of mesoscale or shorter, because a model which correctly captures the small-scale fluctuations but with small spatial or temporal dislocations can be penalized by such scores, i.e. presented large RMSE than a model that is incapable of modeling such fluctuations. Nevertheless, in present experiments, the RMSE decreases with both increasing $c_{k}$ and 2-way nesting, which is consistent with the fact that the large overestimation of wind fluctuation amplitude has been suppressed. With augmenting $c_{k}$, the overestimation of KE was mitigated. However, the model KE is still much larger than that derived from the observations. Further study to understand and improve the discrepancies is recommended.

Finally, snapshots of the simulated wind speed on the 3rd model level of the four experiments, zoomed-in over the three turbine sites for which time series were plotted in Figs. 9 and 11, are shown in Fig. 12. It can be seen that both increasing $c_{k}$ and activating 2-way nesting bring about an overall decrease in the amplitude of the fluctuations. The plots suggest that the 2-way nesting feedback maintains the basic spatial structure of wind fields, but with damped amplitudes of the wind fluctuations. In contrast, increasing $c_{k}$ appears to have increased the size of the smallest spatial structures as well as damped the amplitude of the fluctuations.

\section{Summary and conclusions}

In this paper, we introduce a multi-scale weather model, which is designed for simulation of weather processes from synoptic scales $(\sim 2000 \mathrm{~km})$ to microscales $(\sim 100 \mathrm{~m})$ with simultaneous nested grids. This modeling system, referred to as WRFRTFDDA-LES, is built upon the NCAR Real-Time Four-Dimensional Data Assimilation (RTFDDA) and forecasting system. RTFDDA is built on NCAR community mesoscale Weather Research and Forecasting (WRF) model. The simultaneous multi-scale nested model is capable of simulating small- and micro-scale circulations for regions of high interest, such as wind power farms and metropolitans, on LES modeling grids, seamlessly driven by real large-scale weather forcing. In particular, the FDDA component of the model provides an advanced data assimilation algorithm that is capable of effectively assimilating diverse weather measurements on the mesoscale model grids, and thus produces accurate 

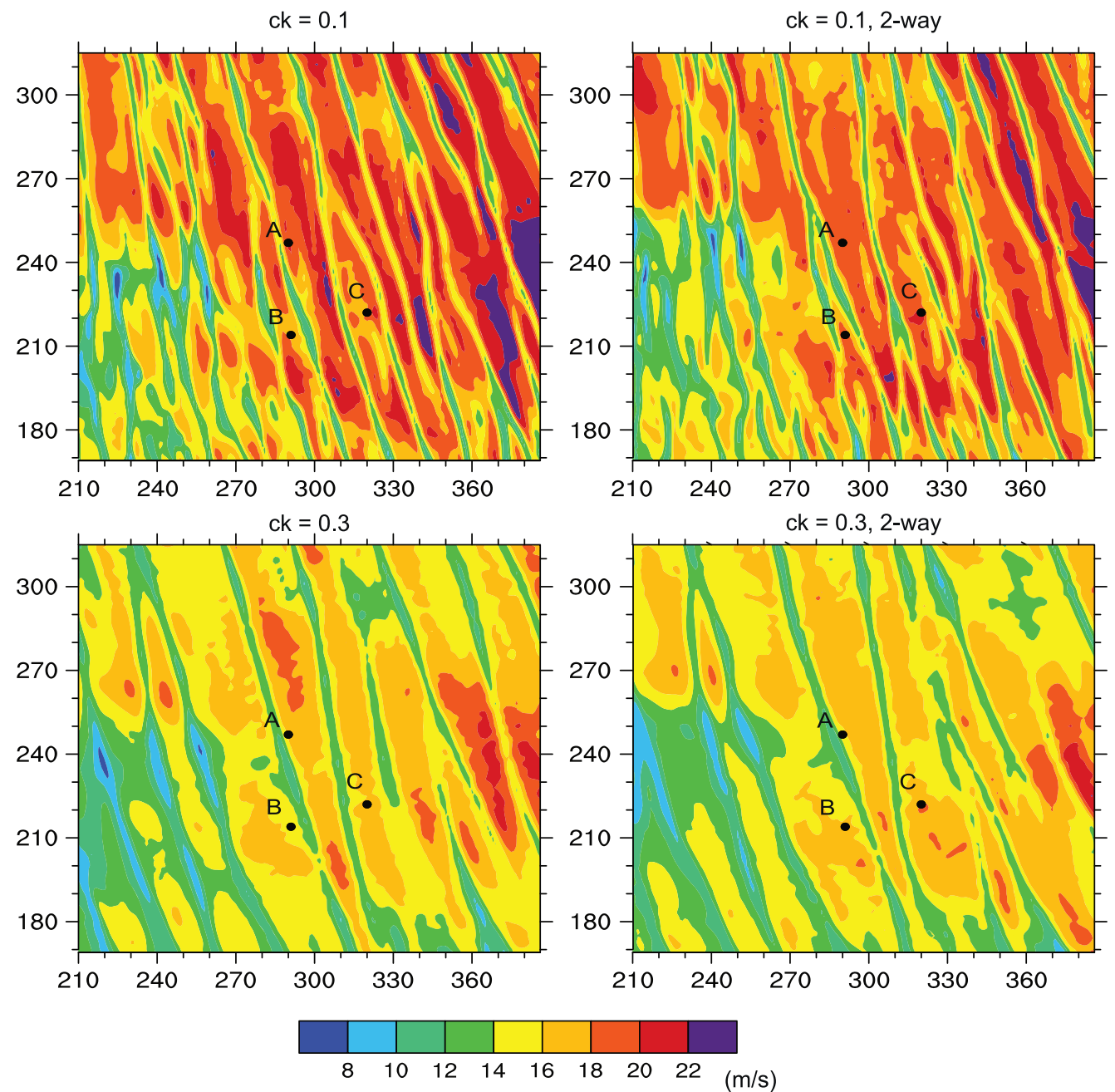

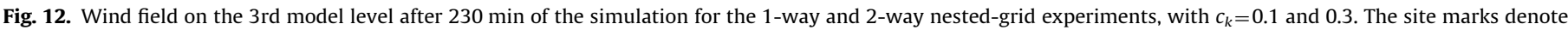

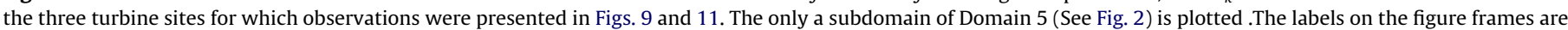
grid numbers in Domain 5.

realistic initial conditions and continuous updates of the environmental forcing to the fine-scale LES modeling through the lateral boundaries.

WRF-RTFDDA-LES was employed to simulate two days (from 18:00 UTC, November 14 to 18:00 UTC, November 16, 2009) of real-case wind circulations at a northern Colorado wind farm, with six simultaneous nested-grid domains at a grid spacing of $30,10,3.3,1.1,0.370$, and $0.123 \mathrm{~km}$, respectively. The four coarse domains were run with mesoscale model settings, including employing column-based PBL mixing and continuous data assimilation, while the two finest mesh domains were run with LES model settings. The WRF-RTFDDA-LES simulated the rich intrafarm wind features and many of them are verified reasonably well against the turbine-hub-height wind speed observations.

Model results and sensitivity studies with WRF-RTFDDA-LES indicates: (a) the advantages of a two-way nesting approach between mesoscale and LES modeling grid; (b) impact of parameter adjustments for 3D prognostic TKE based SGS parameterization; (c) the limitation of mesoscale weather model PBL parameterization for simulation of wind speed and shear in the lowest $300 \mathrm{~m} \mathrm{AGL}$; and (d) the needs for further understanding the transition from full parameterization of large eddies in $\sim 1 \mathrm{~km}$ grid model to explicit modeling of the large eddies in domains with $\sim 10$ m grids.
In spite of the need for developing adaptable SGS diffusion schemes to cope with dominant eddy sizes, including the diurnal evolution and weather-regime-dependent changes of the PBL eddy properties and "wall-effect", and for refining land-surface modeling in WRF to improve its capability for a LES modeling, WRF-RTFDDA-LES provides the unique capability that allows setting LES modeling in real weather scenarios through mesoscale FDDA and time-dependent continuous mesoscale environmental forcing. Thus, this model system can be used to study realistic flows and their forcing factors at given locations, refine LES modeling algorithms, and explore potentials for real-time operational forecasting of the microscale flows in the next few years. The computation for $54 \mathrm{~h}$ simulation with the 6 nested grid domains took about $90 \mathrm{~h}$ wall-clock time on a Dell Linux cluster using 55 dedicated computer nodes (dual Intel Model 4, 3.2 GHz CPUs; 2 Gb RAM per node). It is estimated that a similar size of the new Dell cluster, i.e. a Dell cluster of 50 Intel xeon W3680 nodes can run such a model for $6-8 \mathrm{~h}$ forecasts within two-hour wall-clock windows.

Finally, it should be pointed out that the results reported here are from a single case study. Although more than two days of simulation has been conducted, which includes two diurnal cycles and major weather system activities, the conclusions should be validated with more case scenarios and modeling experiments for 
different weather regimes and different geographical regions. Observations from special field experiments at selected wind farms that provide detailed circulation information of intra-farm microscale flows are desired for validation and verification of model results and for improving the model capabilities and performance. Recently, as new nonlinear subfilter turbulence stress model has been implemented by Mirocha et al. (2010). Testing and evaluating this SGS diffusion in the WRF-RTFDDALES framework is in progress and will be reported in future.

\section{Acknowledgements}

The authors would like to thank Xcel Energy Service Inc., for providing wind farm data used in this study, Dr. Yih-huei Wan of National Renewable Energy Laboratory for advices on wind turbine hub-height wind observation data quality and processing; and Dr. Julie Lundquist of Colorado University and Dr. Chin-Hoh Moeng of NCAR for beneficial discussions, and Drs. Gerry Wiener and Will Y.Y. Cheng, Mr. Brice Lambi and Mr. Gregory Roux at NCAR for assistance in data processing. The computing of this research was performed on the NCAR computers. NCAR is sponsored by the National Science Foundation.

\section{References}

Basu, S., Porté -Agel, F., 2006. Large-eddy simulation of stably stratified atmospheric boundary layer turbulence: a scale dependent dynamic modeling approach. J. Atmos. Sci. 63, 2074-2091.

Chow, F.K., Street, R.L., Xue, M., Ferziger, J.H., 2005. Explicit filtering and reconstruction turbulence modeling for large-eddy simulation of neutral boundary layer flow. J. Atmos. Sci. 62, 2058-2077.

Côté, J., Gravel, S., Méthot, A., Patoine, A., Roch, M., Staniforth, A., 1998. The operational CMC-MRB global environmental multiscale (GEM) model. part I: design considerations and formulation. Mon. Weather Rev. 126, 1373-1395.

Courtier, P., Geleyn, J.-F., 1988. A global numerical weather prediction model with variable resolution: application to the shallow-water equations. Q. J. R. Meteorol. Soc. 114, 1321-1346.

Harris, L.M., Durran, D.R., 2010. On the relative performance of one-way and twoway grid nesting. Mon. Weather Rev. 138, 2174-2187.
Hong, S.-Y., Pan, H.-L., 1996. Nonlocal boundary layer vertical diffusion in a medium-range forecast model. Mon. Weather Rev. 124, 2322-2339.

Janjic, Z.I., 2002. Nonsingular Implementation of the Mellor-Yamada Level 2.5 Scheme in the NCEP Meso model, NCEP Office Note, No. 437, p. 61.

Kosović, B., Curry, J.A., 2000. A large eddy simulation study of a quasi-steady, stably stratified atmospheric boundary layer. J. Atmos. Sci. 57, 1052-1068.

Liu, Y., Chen, F., Warner, T., Basara, J., 2006. Verification of a mesoscale data assimilation and forecasting system for the Oklahoma City area during the Joint Urban 2003 Field Project. J. Appl. Meteorol. Clim. 45, 912-929.

Liu, Y., Warner, T.T., Bowers, J.F., Carson, L.P., Chen, F., Clough, C.A., Davis, C.A., Egeland, C.H., Halvorson, S.F., Huck Jr, T.W., Malone, R.E., Rife, D.L., Sheu, R.-S, Swerdlin, S.P., Weingarten, D.S., 2008a. The operational mesogamma-scale analysis and forecast system of the U.S. Army Test and Evaluation Command: part 1: overview of the modeling system, the forecast products, and how the products are used. J. Appl. Meteorol. Clim. 47, 1077-1092.

Liu, Y., Warner, T.T., Astling, E.G., Bowers, J.F., Davis, C.A., Halvorson, S.F., Rife, D.L., Sheu, R.-S., Swerdlin, S.P., Xu, M., 2008b. The operational mesogamma-scale analysis and forecast system of the U.S. Army Test and Evaluation Command: part 2: inter-range comparison of the accuracy of model analyses and forecasts. J. Appl. Meteorol. Clim. 47, 1093-1104.

Mirocha, J.D., Lundquist, J.K., Kosovic, B., 2010. Implementation of a nonlinear subfilter turbulence stress model for large-eddy simulation in the Advanced Research WRF model. Mon. Weather Rev. 138, 4212-4228.

Moeng, C.-H., Dudhia, J., Klemp, J., Sullivan, P., 2007. Examining two-way grid nesting for large eddy simulation of the PBL using the WRF model. Mon. Weather Rev. 135, 2295-2311.

Skamarock, W.C., Klemp, J.B., Dudhia J., Gill, D.O., Barker, D.M., Duda, M.G., Huang, X.-Y., Wang, W. and Powers, J.G., 2008. A description of the advanced research WRF version 3, NCAR Technical Note.

Smagorinsky, J., 1993. Some historical remarks on the use of nonlinear viscosities. In: Galperin, B., Orszag, S. (Eds.), Large Eddy Simulations of Complex Engineering and Geophysical Flows. Cambridge University Press.

Smolarkiewicz, P.K., and G.A. Grell, 1990. A class of monotone interpolation schemes, J. Comp. Phys., 101, 431-440.

Sullivan, P.P., Horst, T.W., Lenschow, D.H., Moeng, C.-H., Weil, J.C., 2003. Structure of subfilter-scale fluxes in the atmospheric surface layer with application to large-eddy simulation modeling. J. Fluid Mech. 482, 101-139.

Takemi, T., Rotunno, R., 2003. The effects of subgrid model mixing and numerical filtering in simulations of mesoscale cloud systems. Mon. Weather Rev. 11, 2085-2101. 